\title{
NEIGHBORHOODS OF A CERTAIN CLASS OF $p$-VALENT FUNCTIONS WITH NEGATIVE COEFFICIENTS DEFINED BY USING A DIFFERENTIAL OPERATOR
}

\author{
HALIT ORHAN
}

\begin{abstract}
In this present paper, by making use of the familiar concept of neighborhoods of $p$ valent functions, the author prove coefficient bounds and distortion inequalities, and associated inclusion relations for the $(n, \delta)$-neighborhoods of a class of $p$-valently analytic functions with negative coefficients, which is defined by means of a certain non-homogeneous Cauchy-Euler differential equation. Relevant connections of some of the results obtained in this paper with those in earlier works are also provided.
\end{abstract}

Mathematics subject classification (2000): 30C45.

Keywords and phrases: analytic function, $p$-valent functions, Cauchy-Euler differential equation, inclusion relations, $(n, \delta)$-neighborhood, starlike and convex functions, distortion inequalities.

\section{REFERENCES}

[1] Altintaş, O., Irmak, H. ANd SRivastava, H. M., Fractional calculus and certain starlike functions with negative coefficients, Comput. Math. Appl., 30(2) (1995), 9-15.

[2] Salagean, G. S., Subclasses of univalent functions, Lectures Notes in Math., Springer-Verlag, 1013, 362-372, (1983).

[3] KamaLI, M., Neighborhoods of a new class of p-valently starlike functions with negative coefficients, Math. Ineq. Appl. Vol. 9, No. 4, (2006).

[4] Altintaş, O. AND OwA, S., Neighborhoods of certain analytic functions with negative coefficients, Internat. J. Math. and Math. Sci., 19 (1996), 797-800.

[5] Goodman, A. W., Univalent functions and nonanalytic curves, Proc. Amer. Math. Soc., 8, (1975), $598-601$.

[6] RuscheweYH, S., Neighborhoods of univalent functions, Proc. Amer. Math. Soc., 81, (1981), 521-527.

[7] SRIvastava, H. M. AND ORHAN, H., Coefficient inequalities and inclusion relations for some families of analytic and multivalent functions, Appl. Math. Lett., 20 (2007), pp. 686-691.

[8] ALTNTAŞ, O., Neighborhoods of certain p-valently analytic functions, with negative coefficients, Appl. Math. Comp. (2006) (in press).

[9] AltintaŞ, O., ÖZnUR, Ö., AND SRIVASTAVA, H. M., Neighborhoods of a certain family of multivalent functions, with negative coefficients, Comp. Math. Appl., 47 (2004), 1667-1672.

[10] SRIVAStava, H. M., AND Owa, S., (EDS.), Current Topics in Analytic Functions Theory, World Scientific Publishing Company, Singapore, New Jersey, London and Hong Kong (1992).

[11] IRMAK, H., LEE, S. H. AND CHO, N. E., Some multivalently starlike functions with negative coefficients and their subclasses defined by using differential operator, Kyungpook Math. J., 37, 43-51, (1997).

[12] AltinTAŞ, O., ÖZnUR, Ö., AND SRIVASTAVA, H. M., Neighborhoods of a class of analytic functions with negative coefficients, Appl. Math. Lett., 13(3) (2000), 63-67.

[13] ORHAN, H. AND KAMALI, M., Neighborhoods of a class of analytic functions with negative coefficients, Acta Mathematica Academiae Paedagogiace Nyíregyhá ziensi, Vol. 21, No. 1, pp. 55-61 (2005).

[14] ORHAN, H. AND KADIOĞLU, E., Neighborhoods of a class of analytic functions with negative coefficients, Tamsui Oxford Journal of Math. Sci. 20(2), (2004) 135-142. 
[15] ORHAN, H., On neighborhoods of analytic functions defined by using Hadamard Product, Novi Sad Journal of Mathematics, (2007) in press.

[16] Murugusundaramoorthy, G. and SRivastava, H. M., Neighborhoods certain classes of analytic functions of complex order, JIPAM, 5(2), (2004), Article 24, 1-8.

[17] RAINA, R. K. AND SRIVASTAVA, H. M., Inclusion and neighborhood properties of some analytic and multivalent functions, JIPAM, 7 (1), Article 5, (2006), 1-6.

[18] Altintaş, O., On a subclass of certain starlike functions with negative coefficients, Math. Japon. 36, 489-495, (1991). 